\title{
Improvements in SOD mimic AEOL-10150, a potent broad-spectrum antioxidant
}

\author{
Xiao-rui Zhang, Wen-xia Zhou ${ }^{*}$ and Yong-xiang Zhang ${ }^{*}$
}

\begin{abstract}
AEOL-10150 is a broad-spectrum metalloporphyrin superoxidase dismutase (SOD) mimic specifically designed to neutralize reactive oxygen and nitrogen species. Research has shown that AEOL-10150 is a potent medical countermeasure against national security threats including sulfur mustard (SM), nerve agent exposure and radiation pneumonitis following a radiological/nuclear incident sufficient to cause acute radiation syndrome (ARS). AEOL-10150 performed well in animal safety studies, and two completed phase 1 safety studies in patients demonstrated that the drug was safe and well tolerated, indicating that AEOL-10150 has potential as a new catalytic antioxidant drug. In this article, we review improvements in AEOL-10150 in preclinical pharmacodynamic studies, especially regarding anti-SM, chlorine gas and radiation exposure studies.
\end{abstract}

Keywords: Catalytic antioxidant, Metalloporphyrins, Chemical warfare agent, Radiation damage, Pharmacodynamics, Pharmacokinetics

\section{Background}

Superoxide dismutase (SOD) is a cytoprotective enzyme [1]. The SOD pioneer Fridovich first synthesized pyridine quaternary ammonium water-soluble manganoporphyrin to mimic the Mn-SOD catalytic site [2, 3], after which a series of compounds were reported. AEOL is a type of metalloporphyrin catalytic antioxidant developed by US Aeolus pharmaceuticals that possesses SOD- and catalase-like activity. As a leading AEOL compound, AEOL-10150 was studied as a medical treatment against acute radiation-induced lung injury using the biomedical advanced research and development authority's \$118 million 5-year grant. In follow-up research, Aeolus pharmaceuticals uncovered additional AEOL-10150 biological activities for treating sulfur mustard (SM), chlorine gas and nerve agent exposure and acquired an National Institutes of Health (NIH) grant to develop AEOL-10150 as an anti-chemical warfare agent [4]. If the project is successful, AEOL-10150 would be stocked in the U.S. Strategic National Stockpile (SNS).

AEOL-10150 is also known as MnTDE-2-ImP5 ${ }^{+}$, with the molecular formula C48-H56-Mn-N12.5-Cl and a molecular weight of 1033.257 . Structurally, SOD mimics

\footnotetext{
* Correspondence: zhouwx@bmi.ac.cn; zhangyx@bmi.ac.cn

State Key Laboratory of Toxicology and Medical Countermeasures, Beijing Institute of Pharmacology and Toxicology, Beijing 100850, China
}

are characterized by a modified alkylated pyridyl quaternary ammonium group at the meta position of the porphyrin ring. Coordination manganese ions are generally +3 charges (Fig. 1a). Studies show that the position of the $\mathrm{N}$ atom on meso-pyridine significantly affects manganese porphyrin activity and that the more active the pyridine $\mathrm{N}$ is, the closer it is to the metal catalyst center [5]. Among the AEOL series compounds, the activities of water-soluble AEOL-10150 compounds deserve attention. Recent reports have shown that AEOL-1114 and AEOL-11203 exhibit good lipophilicity and, upon oral administration, can pass through the blood cerebrospinal fluid barrier (Fig. 1b, c) [6]. In addition, Aeolus improved the production of AEOL-10150 in terms of drug stability, reducing costs by $90 \%$, and confirmed that new synthetic AEOL-10150 is stable at room temperature and under refrigerated conditions up to 24 months; stability testing will continue to 60 months [7].

Aeolus pharmaceuticals announced that AEOL-10150 achieved excellent safety results in both animal and human experiments. One of the two clinical studies of 50 patients (at least 39 patients with amyotrophic lateral sclerosis (ALS)) confirmed that AEOL-10150 did not cause serious side effects and was well tolerated, although skin spots were caused by discoloration and continuous infusion at the injection site [8]. AEOL-10150 was approved

(C) The Author(s). 2018 Open Access This article is distributed under the terms of the Creative Commons Attribution 4.0 International License (http://creativecommons.org/licenses/by/4.0/), which permits unrestricted use, distribution, and reproduction in any medium, provided you give appropriate credit to the original author(s) and the source, provide a link to the Creative Commons license, and indicate if changes were made. The Creative Commons Public Domain Dedication waiver (http://creativecommons.org/publicdomain/zero/1.0/) applies to the data made available in this article, unless otherwise stated. 


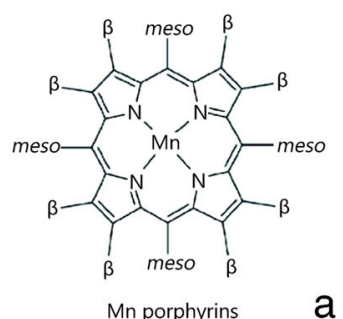

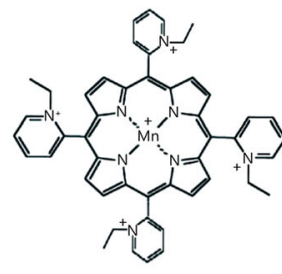

AEOL-10113

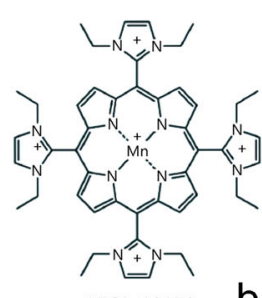

AEOL-10150
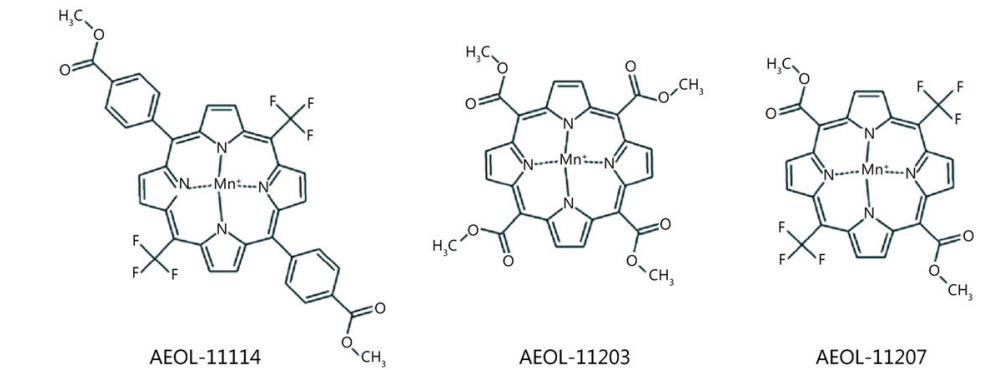

AEOL-11207

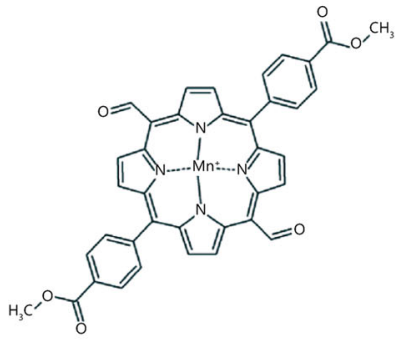

AEOL-11209

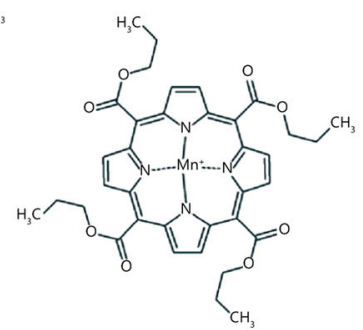

AEOL-11215

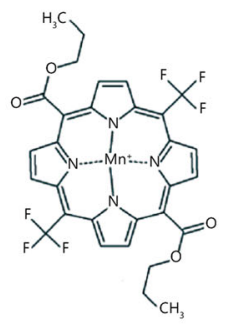

AEOL-11216 C

Fig. 1 The structure of AEOL compounds. a. Structural scheme of the Mn porphyrins of SOD mimics; $\mathbf{b}$. Water-soluble compounds of Mn porphyrins; c. Lipid-soluble compounds of Mn porphyrins

by the Food and Drug Administration (FDA, fast track designation) for treating patients with lung acute radiation syndrome (ARS) (Table 1). The new and old formulations of AEOL-10150 have been reported to exhibit similar toxicity and pharmacokinetic characteristics, and more importantly, the new formulation of AEOL-10150 exhibits less irritation and has higher bioavailability. Based on prepharmacy, animal-level pharmacodynamics, toxicology, and pharmacokinetics studies, Aeolus announced the launch of a new AEOL-10150 formulation for human phase I clinical trials in healthy volunteers and/or to test its potential to treat pulmonary fibrosis patients by evaluating its safety, tolerance and pharmacokinetics [4]. In this article, we focus on AEOL-10150 advances in preclinical pharmacodynamics, especially anti-SM, chlorine gas and radiation exposure studies.

\section{Anti-chemical warfare agent exposure by AEOL-10150 Anti-sulfur mustard exposure}

AEOL-10150 has broad-spectrum antioxidant activity, including the removal of $\mathrm{O}_{2}^{-}, \mathrm{H}_{2} \mathrm{O}_{2}, \mathrm{ONOO}^{-}, \mathrm{NO}$ and lipid peroxides [9-11]. The indications mainly focus on treating SM, nerve agents and other chemical warfare agents (Table 2), and radiation damage (Table 1) and other oxidative stress-related diseases. SM is a vesicating and alkylating chemical warfare agent with extremely high activity for which there is still no antidote. The SM analog 2-chloroethyl ethyl sulfide (CEES) has been used to study the mechanisms of SM intoxication and to screen for antidotes. One study showed that post-treatment with AEOL-10150 reduces CEES-induced lung injury in rats exposed to 5\% CEES for 15 min with a nose-only inhalation system. The rats were then injected with $5 \mathrm{mg} / \mathrm{kg}$ AEOL-10150 subcutaneously $1 \mathrm{~h}$ and $9 \mathrm{~h}$ after CEES exposure to observe antitoxic effects. The results showed that lactate dehydrogenase, protein, IgM, erythrocyte and neutrophil levels significantly increased in the bronchoalveolar lavage fluid of rats $18 \mathrm{~h}$ after exposure, and AEOL-10150 treatment significantly inhibited these affects. This study also found that myeloperoxidase (MPO) activity significantly increased in the lungs of rats after inhalation and was significantly reduced after AEOL-10150 administration. In addition, the oxidative stress markers 8-OHdG and 4-hydroxynonenal (4-HNE) also increased significantly after exposure and significantly decreased after AEOL-10150 treatment. This study showed that CEES inhalation clearly 
Table 1 Improvements in AEOL-10150 regarding antiradiation diseases released by Aeolus Pharmaceuticals

\begin{tabular}{|c|c|}
\hline Time $(M / D / Y)$ & Contents \\
\hline $04 / 15 / 2008$ & AEOL-10150 protects lungs against fractionated radiation damage and inhibits angiogenesis and inflammation \\
\hline 07/06/2009 & AEOL-10150 significantly improves survival in mice exposed to radiation when administered after exposure \\
\hline 09/08/2009 & Initiates study of AEOL-10150 as a treatment against radiation exposure in nonhuman primates \\
\hline $11 / 17 / 2009$ & $\begin{array}{l}\text { Duke University initiates study of AEOL-10150 to observe the compound's activity protecting healthy tissue in mice } \\
\text { receiving chemotherapy and radiation for non-small-cell lung cancer }\end{array}$ \\
\hline $04 / 12 / 2010$ & $\begin{array}{l}\text { Proclaims the initiation of a second study of AEOL-10150 as a medical treatment against Gl acute radiation syndrome } \\
\text { funded by the NIH's National Institute for Allergy and Infectious Diseases }\end{array}$ \\
\hline $11 / 02 / 2010$ & AEOL-10150 improves survival in nonhuman primates exposed to lethal doses of radiation \\
\hline $02 / 08 / 2012$ & AEOL-10150 protects lung tissue from radiation by regulating PTEN levels and inhibiting oxidative stress and apoptosis \\
\hline 06/01/2012 & AEOL-10150 alleviates lung damage after Neupogen treatment following radiation exposure \\
\hline $09 / 17 / 2013$ & $\begin{array}{l}\text { BARDA exercises } \$ 6.0 \mathrm{~mm} \text { in additional contract funding to develop AEOL-10150 as countermeasure against acute } \\
\text { radiation syndrome }\end{array}$ \\
\hline 10/29/2013 & AEOI-10,150 significantly increases survival and protects lungs in mice exposed to lethal radiation \\
\hline 08/20/2014 & $\begin{array}{l}\text { Aeolus files an investigational new drug application with the FDA to enable the initiation of human safety studies } \\
\text { for the development of AEOL-10150 as a medical treatment against lung damage from radiation exposure }\end{array}$ \\
\hline $09 / 04 / 2014$ & $\begin{array}{l}\text { Proclaims positive results from a study showing AEOL-10150 doubles the survival rate following lung damage caused } \\
\text { by acute radiation exposure }\end{array}$ \\
\hline $05 / 04 / 2015$ & $\begin{array}{l}\text { Aeolus proclaims complete results from a successful study showing AEOL-10150 doubles survival rate following lung } \\
\text { damage from acute radiation exposure }\end{array}$ \\
\hline $06 / 26 / 2015$ & $\begin{array}{l}\text { BARDA exercises } \$ 3 \mathrm{~mm} \text { in additional contract funding for the development of } \mathrm{AEOL}-10,150 \text { as a countermeasure } \\
\text { to acute radiation syndrome }\end{array}$ \\
\hline 06/08/2017 & $\begin{array}{l}\text { FDA fast track designation granted to AEOL-10150 for treatment of patients with lung acute radiation syndrome } \\
\text { following a radiological or nuclear event }\end{array}$ \\
\hline
\end{tabular}

Table 2 Improvements in AEOL-10150 in terms of use as an anti-chemical warfare agent released by Aeolus Pharmaceuticals

\begin{tabular}{|c|c|}
\hline Time $(M / D / Y)$ & Contents \\
\hline $11 / 07 / 2007$ & AEOL-10150 protects SM-induced lung damage \\
\hline $04 / 23 / 2008$ & AEOL-10150 significantly protects against SM-exposure-induced lung and skin damage \\
\hline 02/09/2009 & NIH Counter ACT program begins assessing treatment with Aeolus pharmaceuticals' AEOL-10150 against SM gas damage \\
\hline 10/07/2009 & AEOL-10150 protects lungs against SM damage in animal research \\
\hline $11 / 04 / 2009$ & AEOL-10150 protects lungs against $\mathrm{Cl}_{2}$ exposure in animal research \\
\hline $06 / 29 / 2010$ & AEOL-10150 significantly protects skin in preclinical SM damage studies \\
\hline $06 / 30 / 2010$ & AEOL-10150 protects lungs against SM exposure in animal research \\
\hline 10/10/2011 & $\mathrm{NIH}$ grant of $\$ 12.7$ million awarded to continue development of $\mathrm{AEOL-10150}$ as a countermeasure to $\mathrm{Cl}_{2}$ and $\mathrm{SM}$ damage \\
\hline $10 / 24 / 2011$ & Aeolus pharmaceuticals announces NIH award to develop AEOL-10150 as a countermeasure to nerve agent exposure \\
\hline 07/30/2012 & AEOL-10150 announced to eliminate oxidative stress and nerve damage following exposure to nerve agent \\
\hline $06 / 26 / 2013$ & AEOL-10150 significantly ameliorates survival in animals exposed to SM \\
\hline 07/02/2013 & AEOL-10150 significantly ameliorates survival from nitrogen mustard exposure to skin in animals \\
\hline $09 / 11 / 2013$ & $\begin{array}{l}\text { AEOL-10150 is the subject of a } \$ 4.3 \text { million US government award defining countermeasures to nerve agents; data show that } \\
\text { the drug significantly ameliorates survival in animals following exposure to pilocarpine, a nerve agent surrogate for soman } \\
\text { and sarin gas }\end{array}$ \\
\hline $06 / 18 / 2014$ & Aeolus proclaims the publication of data demonstrating the efficacy of AEOL-10150 in an animal CEES model of SM skin damage \\
\hline 07/01/2014 & $\begin{array}{l}\text { Aeolus proclaims additional data demonstrating efficacy of AEOL-10150 as a medical treatment against exposure to nerve agents, } \\
\text { SM and nitrogen mustard gas }\end{array}$ \\
\hline 03/31/2015 & $\begin{array}{l}\text { Aeolus receives a notice of allowance from the Israeli patent office for the use of AEOL-10150 and other Aeolus compounds to } \\
\text { treat damage from exposure to SM }\end{array}$ \\
\hline 09/06/2016 & Aeolus proclaims positive data demonstrating the efficacy of AEOL-10150 as a medical treatment against SM \\
\hline $09 / 19 / 2016$ & $\begin{array}{l}\text { Aeolus proclaims publication of additional data showing the efficacy of AEOL-10150 in SM exposure in the journal Toxicological } \\
\text { Sciences }\end{array}$ \\
\hline
\end{tabular}


causes lung injury, inflammation and oxidative stress that can be significantly antagonized by AEOL-10150 [12]. Studies have found that CEES inhalation leads to extensive olfactory epithelium (OE) damage. AEOL-10150 reduces $\mathrm{OE}$ damage both subcutaneously $(5 \mathrm{mg} / \mathrm{kg})$ and combined with intranasal administration $(50 \mu \mathrm{mol} / \mathrm{L})$ [13], indicating that AEOL-10150 is a countermeasure candidate for SM-induced lung injury.

Studies have also monitored the effects of AEOL10150 on CEES-induced skin damage. Administration of AEOL-10150 (50 $\mu \mathrm{mol} / \mathrm{L}) 1 \mathrm{~h}$ after CEES exposure significantly reversed the CEES-induced necrosis of murine epidermal JB6 cells, human $\mathrm{HaCaT}$ cells and normal human epidermal keratinocytes and reduced DNA damage. AEOL-10150 also drastically ameliorated the cytoplasmic and mitochondrial active oxygen free radicals in JB6 and $\mathrm{HaCaT}$ cells to reduce skin damage. This study indicated that AEOL-10150 has potential therapeutic efficacy against CEES-mediated skin lesions and supports AEOL-10150 as an effective medical countermeasure against skin lesions caused by SM [14].

Recent research studied the effect of AEOL-10150 on SM exposure. Adult male rats were intubated, followed by SM $(1.4 \mathrm{mg} / \mathrm{kg})$ exposure, which exhibits an LD50 at approximately $24 \mathrm{~h}$. Rats were injected subcutaneously with sterile PBS or AEOL-10150 (subcutaneous injection, every $4 \mathrm{~h}$, $5 \mathrm{mg} / \mathrm{kg}$ ) beginning $1 \mathrm{~h}$ post-SM exposure. Notably, catalytic antioxidant treatment improved survival after SM inhalation in a dose-dependent manner, and the survival rate of animals in the administration group was as high as $52 \%$ at $48 \mathrm{~h}$ after SM exposure. The drug also maintained a $72 \mathrm{~h}$ response when treatment was terminated $48 \mathrm{~h}$ after SM exposure. The test results showed that the oxygen saturation of treated animals increased by $10 \%$, and the clinical score reduced by $57 \%$. Tissue analysis revealed a $69 \%$ reduction in airway tube formation in treated animals within $48 \mathrm{~h}$ of SM exposure. To determine the effect of drug treatment at peak injury, changes in oxidative stress markers were observed $24 \mathrm{~h}$ after SM exposure. AEOL-10150 significantly reduced SM-induced lung injury by reducing lung lipid peroxidation and inhibiting the release of multiple proinflammatory cytokines, suggesting that catalytic antioxidants are effective measures of SM inhalation injury [15]. The above results indicate that AEOL-10150 might be an effective anti-SM treatment agent. In future research, AEOL-10150 anti-mustard gas research should elucidate the molecular mechanisms and targets of drug efficacy. Understanding these mechanisms would help elucidate the mechanism of mustard gas poisoning and significantly drive the development of anti-SM drugs.

\section{Antichlorine-induced lung injury}

Chlorine $\left(\mathrm{Cl}_{2}\right)$ is a typical asphyxial chemical reagent, and rescue treatment after $\mathrm{Cl}_{2}$ exposure is under intense

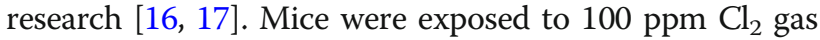
for $5 \mathrm{~min}$ and then divided into four groups: the chlorine only exposure group, treated with AEOL-10150 $1 \mathrm{~h}$ and $9 \mathrm{~h}$ after chlorine exposure group; the AEOL-10150 only group; and the control group. An experimental small animal ventilator was used to measure airway responsiveness to aerosolized methacholine $(6.25-50 \mathrm{mg} / \mathrm{ml}) 24 \mathrm{~h}$ after $\mathrm{Cl}_{2}$ gas exposure, and bronchial alveolar lavage (BAL) was used to assess airway inflammation and protein. The 4-hydroxynonenal in whole lung tissue was tested. Lung tissue from different groups of animals was collected $72 \mathrm{~h}$ after $\mathrm{Cl}_{2}$ exposure to measure epithelial cell proliferation. Compared to other groups, mice exposed to $\mathrm{Cl}_{2}$ showed significantly higher airway resistance in response to methacholine challenge. AEOL-10150 significantly attenuated the increase in neutrophils and macrophages in the BAL of $\mathrm{Cl}_{2}$-exposed mice. AEOL-10150 significantly inhibited the $\mathrm{Cl}_{2}$-induced increase in BAL fluid protein and also attenuated the $\mathrm{Cl}_{2}$-induced increase in epithelial cell proliferation. AEOL-10150 significantly reduced 4-HNE levels after $\mathrm{Cl}_{2}$ exposure. The above results indicate that AEOL-10150 is an effective treatment for $\mathrm{Cl}_{2}$-induced airway hyperresponsiveness, airway inflammation, airway epithelial cell proliferation and oxidative stress [18]. The above results indicate that AEOL-10150 may be a potent inhibitor of $\mathrm{Cl}_{2}$ damage including airway hyperresponsiveness, airway inflammation, oxidative stress and epithelial cell proliferation. In future studies, AEOL-10150 anti- $\mathrm{Cl}_{2}$ research should further elucidate the targets for drug efficacy to elucidate the mechanism of $\mathrm{Cl}_{2}$ poisoning and promote the success rate of research and development of anti- $\mathrm{Cl}_{2}$ drugs.

\section{Anti-radiation exposure of AEOL-10150}

Radiation damage is closely related to free radical release [19-21]. Studies have shown that chronic administration of the SOD mimic AEOL-10150 has a protective effect on radiation-induced lung injury, whereas low-dose or short-term AEOL-10150 treatment has no effect on radiation-induced lung injury [22, 23]. Early studies have found that the chronic sustained expression of extracellular SOD (EC-SOD) protects lungs from radiotherapy-induced injury. Therefore, AEOL-10150 is used to treat lung injury after radiotherapy [24]. The results showed that the respiratory rate of Fisher-344 rats increased 8 weeks after radiotherapy (28 Gy), reaching a peak at 18 weeks. Low-dose AEOL-10150 via osmotic pump (1 mg/(kg.d)) conferred no protection against radiotherapy-induced injury. Compared with the model group, the experimental animals of the medium- and high-dose AEOL-10150 administration groups (10 and $30 \mathrm{mg} /(\mathrm{kg} . \mathrm{d})$ ) showed significantly decreased respiratory rates. Immunohistochemistry showed that the number of 
macrophages in the middle- and high-dose groups was significantly reduced [25].

Recently, a study examined the effect of AEOL-10150 on lethal lung radiation injury (10.74 Gy, $0.80 \pm 0.05 \mathrm{~Gy} / \mathrm{min}$ ) of rhesus macaque lungs. The researchers designed three treatment options, including radiotherapy day 1 -day 28 , day 1 -day 60 or a divided regimen day 1 -day 28 plus day 60 -day 88 . The results showed that only the day 1 -day 60 administration schedule improved survival from 25 to $50 \%$, with an average survival time of decedents and latency to a non-sedated respiratory rate of $>60$ or $>80$ breaths/min; furthermore, lung injury was eliminated. This treatment did not improve the incidence of pneumonitis or the severity of fibrosis. The Kaplan-Meier survival curves indicated that treatment efficacy could be strengthened by lengthening treatment time to 90 days or longer after lung irradiation [26]. Another nonhuman primate model showed that treatment with AEOL-10150 (5 mg/kg) for 1 month resulted in $28.6 \%$ survival following exposure to a radiation dose of 11.5 Gy that proved to be $100 \%$ fatal in control animals. The AEOL-10150-treated group required less dexamethasone support during the survival phase of the study. Compared with the control cohort, the AEOL-10150 treatment group showed lower plasma TGF- $\beta_{1}$ levels [27].

In addition, the ability of AEOL-10150 to reduce the severity of long-term lung injury caused by fractionated radiotherapy (RT) has been assessed. The experimental rats were randomly divided into 5 groups: $\mathrm{RT}+2.5 \mathrm{mg} / \mathrm{kg}$ AEOL-10150, RT +5 mg/kg AEOL-10150, AEOL-10150 $2.5 \mathrm{mg} / \mathrm{kg}$ group, AEOL-10150 $5 \mathrm{mg} / \mathrm{kg}$ group and RT. The right hemithorax received five 8 Gy fractions of RT. After 26 weeks, lung tissue showed that lung injury and collagen deposition in the $5 \mathrm{mg} / \mathrm{kg}$ AEOL-10150 treatment group significantly decreased compared with that in the RT alone group. The research also showed significant reduction in hypoxia inducible factor- $1 \alpha$ (HIF1 $\alpha)$, Vascular endothelial growth factor, CD-31, Fibroblast growth factor receptor 2 IIIc (ED-1), 8-hydroxy-2 deoxyguanosine (8-OHdG), 3-nitrotyrosine, transforming growth factor $\beta_{1}\left(\mathrm{TGF} \beta_{1}\right)$, Small mother against decapentaplegic 3 (Smad3), and p-Smad2/3 in animals in the $\mathrm{RT}+5 \mathrm{mg} / \mathrm{kg}$ AEOL-10150 group. Although the administration of AEOL-10150 (5 mg / $/ \mathrm{kg}$, bid) during and after RT had a significant protective effect on lung injury, the low-dose AEOL-10150 (2.5 mg/kg bid) administration group exhibited no significant effect $[28,29]$. Related research additionally identified 44 genes associated with oxidative stress, cell growth, inflammation, extracellular matrix synthesis metabolism and apoptosis that increased after radiation. In the animals treated with AEOL-10150, most genes with increased expression attenuated, indicating that some hypoxia-related genes effectively regulated after irradiation [30]. The anti-radiation effect of AEOL-10150 may partially relate to its apoptotic inhibition. Normal lung tissues several weeks after RT showed I and II type pneumocytes and endothelial cell apoptosis. Furthermore, apoptosis-related signaling pathways revealed that PTEN expression increased, the PI3K/AKT signal was inhibited, and p53 and Bax protein expression levels increased, which might be related to radiation-induced increases in TGF- $\beta_{1}$, NADPH oxidase 4 (Nox4) and oxidative stress. After $2 \mathrm{~h}$ of irradiation, AEOL-10150 (20 mg/(kg.d), once every other day for 4 weeks) restored PTEN and the downstream proapoptotic signal to normal levels and reduced apoptosis [31]. A study also found that AEOL-10150 had a positive effect on the incidence and duration of gastrointestinal repair and radiation-induced oral mucositis after RT [32]. Although the above studies evaluated the effects of AEOL-10150, compared with other antioxidants, against radiation damage and elucidated some of the molecular mechanisms, the main target of AEOL-10150 and the characteristics of its effects remain unclear.

\section{Other pharmacodynamics of AEOL-10150 Lung injury protection}

Smoking leads to respiratory inflammation and epithelial damage, and smoke itself or the persistent inflammation generated by free radicals can be important driving forces [33]. For example, the number of cells recovered from bronchoalveolar lavage was significantly elevated after tobacco smoke exposure of either 2 days or 8 weeks $(6 \mathrm{~h} / \mathrm{d}, 3 \mathrm{~d} /$ week). AEOL-10150 significantly reduced bronchoalveolar lavage cell number in tobacco smoketreated rats. Obvious decreases in neutrophil numbers were observed at $2 \mathrm{~d}$ and in macrophages after 8 weeks. Lymphocytes were significantly decreased by AEOL10150 at both time points. After 8 weeks of exposure to tobacco smoke, the number of squamous metaplasia treated with AEOL-10150 decreased from 12\% of the total airway epithelial area to $2 \%$. The results show that AEOL-10150 has a protective effect on smoking-induced bronchial lung injury [34]. In addition, studies have found that AEOL-10150 also reduces the remodeling of smoking-induced lung tissue [35]. The protective effect of AEOL-10150 on smoking-induced lung injury may also be associated with the role of AEOL-10150 in controlling Nuclear factor $\kappa \mathrm{B}(\mathrm{NF}-\mathrm{\kappa B})$ activation, affecting histone modification and expression of inflammatory genes $[36,37]$. As oxidative stress and chronic inflammation are also important pathologic features of chronic obstructive pulmonary disease (COPD) [38, 39], it was concluded that AEOL-10150 might be beneficial for the treatment of COPD.

\section{Cerebral ischemia-reperfusion injury protection}

Oxidative stress is an important cause of cerebral ischemia-reperfusion injury [40]. The effect of AEOL-10150 on middle cerebral artery occlusion (MCAO) was observed. 
Rats were intraperitoneally injected with AEOL-10150 for $90 \mathrm{~min}$ after reperfusion for $90 \mathrm{~min}$. The results showed that AEOL-10150 significantly reduced infarct size (35\%) and neuronal loss, and in the ischemic cerebral hemisphere, AEOL-10150 uptake was time and dose-dependent. AEOL-10150 inhibited lactate dehydrogenase release in a dose-dependent manner in a neuronal/ glia mixed culture system deprived of oxygen and glucose for $2 \mathrm{~h}$ and selectively retained aconitase at concentrations consistent with neuroprotection as assessed by an in vivo enzyme activity. The results of this study indicate that AEOL-10150 has a wide therapeutic window range and neuroprotective activity [41]. In addition, AEOL-10150 intravenous administration to treat ischemia-reperfusion also has a significant therapeutic effect. Studies have shown that AEOL-10150 administration decreased the cerebral infarction area by $40 \%$ and significantly improved nervous system function in $\mathrm{C} 57 \mathrm{BL} / 6 \mathrm{~J}$ mice subjected to $60 \mathrm{~min}$ of MCAO with the pericranial temperature controlled at $37{ }^{\circ} \mathrm{C}$ [42]. Similarly, C57BL/6 J mice were treated with AEOL-10150 intravenously for $5 \mathrm{~min}$ on the right $\mathrm{MCAO}$ and $5 \mathrm{~min}$ after reperfusion. Stress and inflammatory response-related gene expression changed significantly, including HSP (heat shock protein), IL-6, and MIP-2 (macrophage inflammatory protein-2). AEOL-10150 treatment is limited to inhibiting the expression of inflammatory genes. [43]. These results suggest that AEOL-10150 can effectively reduce ischemic brain damage if administered intravenously at an early stage of reperfusion after cerebral ischemia, and its mechanism may be partly related to a reduced inflammatory response.

\section{Spinal cord injury protection}

Spinal cord injury is closely related to ROS [44]. AEOL-10150 also has protective effects on mouse spinal cord injury. Studies have evaluated the efficacy of AEOL-10150 in spinal cord compression (SCC) mice and showed that AEOL-10150 (0.5 mg/kg rapid injection and then $1 \mathrm{mg} /(\mathrm{kg} \cdot \mathrm{h})$ continuous administration for $24 \mathrm{~h}$ ) given intravenously $5 \mathrm{~min}$ after injury in SCC model mice or treatment with methylprednisolone $(30 \mathrm{mg} / \mathrm{kg}$ injection, and then $5.4 \mathrm{mg} /(\mathrm{kg} \cdot \mathrm{h})$ for $24 \mathrm{~h}$ ) had no significant effect on the rotation test or the total lesion score. However, if intradermal administration was used, AEOL-10150 (2.5 or $5.0 \mathrm{mg}$ ) improved both the rotation test and total damage score compared with the control group. This study shows that the therapeutic effect of SCC on AEOL-10150 depends on its concentration in the central nervous system $[45,46]$.

\section{Anti-amyotrophic lateral sclerosis}

It is well known that mice overexpressing the human $\mathrm{Cu}, \mathrm{Zn}$ SOD1 mutant G93A gradually develop delayed and progressive motor neuron diseases similar to human ALS [47]. Studies have shown that if AEOL-10150 (intraperitoneal injection) at an initial dose of $5.0 \mathrm{mg} / \mathrm{kg}$ and a maintenance dose of $2.5 \mathrm{mg} /(\mathrm{kg} \cdot \mathrm{d})$ is started at the onset of symptoms, the animal survival period can be effectively prolonged 3.0-fold. Spinal cord immunohistochemistry results showed that AEOL-10150 treatment induced expression of the SMI-32 protein and that the protein in motor neurons has a high level of expression. The results showed that AEOL-10150-treated spinal cord motor neurons had better-preserved architecture with fewer astroglial cells (glial fibrillary acidic protein) and significantly less nitrotyrosine and malondialdehyde. These results demonstrate that AEOL-10150 has a definite therapeutic effect on ALS onset [48]. In addition, the study found that the use of AEOL-10150 alone or the histone deacetylase inhibitor phenylbutyric acid (PBA) significantly enhanced motor function and prolonged survival by $11 \%$ and $13 \%$, respectively. The combined application of PBA and AEOL-10150 significantly extended survival by $19 \%$ [49]. Drugs evaluated based on the SOD1 mouse model failed to identify drugs effective for human ALS treatment, leading to questions regarding whether these preclinical data could be used for human disease research. Subgroup analysis indicated that COX-2 inhibitors with anti-inflammatory activity, the antibiotic minocycline, and the antioxidant creatine or AEOL-10150 are the most promising prophylactic and therapeutic agents for patients with familial ALS [50].

\section{Islet cell protection}

For many reasons, a significant reduction in the amount of transplantable islet cells occurs [51]. The researchers found that adding SOD mimetics significantly increased islet cell survival. The function and phenotypic characteristics of islets treated with SOD were preserved, and even transplanted peripheral cells of islet tissue restored function to diabetic mice. Further inhibition of islet cell loss can be achieved if SOD mimetics are added earlier. [52]. It has been further found that AEOL-10150 significantly reduces NF- $\mathrm{kB}$ binding to DNA, inhibiting the release of inflammatory cytokines and chemokines as well as the activation of poly ADP-ribose polymerase (PARP) polymerase, resulting in greater survival and much better insulin release [53]. A similar study found that the best dosage able to fully counteract mechanical stress was $100 \mu \mathrm{mol} / \mathrm{L}$. At dosages $\geq 150 \mu \mathrm{mol} / \mathrm{L}$, the compound was toxic for islet cells. In contrast, AEOL-10150 offers no protection against rIL-1 $\beta$-induced islet cell chemical stress damage [54]. These results suggest that antioxidants are beneficial for reducing islet cell damage and have a significant effect on islet transplantation.

\section{Effects on the cardiovascular system}

EC-SOD has protective effects on myocardial ischemia, pulmonary inflammation and fibrosis [55]. Studies have 
shown that, compared with wild-type mice, EC-SOD knockout mice have thinner left ventricular walls, increased end-diastolic volume, increased cardiomyocyte apoptosis, and left ventricular fibrosis and inflammatory cell infiltration. Doxorubicin can cause oxidative stress in the heart. Doxorubicin can further elevate cardiomyocyte apoptosis and left ventricular fibrosis and inflammatory cell infiltration in EC-SOD knockout mice, whereas AEOL-10150 eliminates cardiac dysfunction and myocardial fibrosis in doxorubicin-induced wild-type mice and EC-SOD knockout mice [56]. Endothelin-1 (ET-1) is a vasoconstrictor and mitogen peptide that regulates and maintains blood pressure $[57,58]$. Because oxidative stress activates the vasoconstrictor system, ET-1 is closely linked to pulmonary and cardiovascular diseases, including congestive heart failure, atherosclerosis, and hypertension $[59,60]$. Therefore, SOD mimics have been proposed to be used to observe the role of ET-1 in the endothelin system. Subcutaneous injection of AEOL-10150 (2 or $5 \mathrm{mg} / \mathrm{kg}$ ) after $2 \mathrm{~h}$ and $24 \mathrm{~h}$ has been reported to significantly reduce Fischer-344 male rat isoeperolane $(-25 \%)$ and 3-nitrotyrosine $(-50 \%)$, and the decreased oxidative stress markers were consistent with decreased plasma ET-1 $(-50 \%)$ and the related endothelin ET-3 (-10\%) within $24 \mathrm{~h}$. Although PreproET-1 and endothelin-1 (ECE-1) mRNA levels did not change in the lungs, there was a significant increase in preproET-1 and ECE-1 mRNA levels (10-25\%). Lung ET-1 clearance receptor and vasoconstriction-signal ETA receptor mRNA levels were significantly decreased; iNOS severely strongly initially but persistently declined by $40 \%$ in $24 \mathrm{~h}$. The results suggest that AEOL-10150 regulates the endothelin/ nitric oxide system by inhibiting endogenous ROS and RNS [61].

\section{Immune regulation}

Manganese porphyrins are considered the most active free radical scavengers, in which $\mathrm{Mn}$ is positively charged and reacts with negatively charged free radicals such as $\mathrm{O}_{2}{ }^{-}$and $\mathrm{ONOO}^{-}$. Some researchers believe that the antioxidantregulated redox reaction may be beneficial for the control of inflammation-related diseases [62]. To validate this hypothesis, researchers have observed the effects of AEOL-10150 on LPS-induced secretions of the proinflammatory cytokines TNF- $\alpha, \mathrm{IL}-1 \beta$ and free radical $\mathrm{NO}_{2}{ }^{-}$and $\mathrm{O}_{2}{ }^{-}$. Antioxidants inhibited free radical and proinflammatory cytokine production and were associated with the inhibition of NF- $\mathrm{kB}$ binding to DNA, independent of MAPK signaling pathways [63]. Compared with pulmonary hemorrhage in wild-type mice, in EC-SOD-deficient mice $1 \mathrm{~h}$ after pulmonary hemorrhage neutrophil aggregation, myeloperoxidase activity was increased 3.9 times, and NF- $\mathrm{KB}$ and lipid peroxidation enzyme activity was increased by 1.5 times. Prophylactic administration of AEOL-10150 significantly reduced NF-kB and lipid peroxidase activity in both wild-type and EC-SOD-deficient mice [64]. In addition, manganese porphyrin has been reported to inhibit transcription factors HIF-1 $\alpha$, AP-1 and SP-1 [65]. The above studies suggest that catalytic antioxidants can be used for the treatment of inflammatory-related diseases.

\section{Antitumor}

Antioxidants have protective effects on radiation damage in normal tissues, but the effects on radiotherapy-receiving tumor cells are unclear $[66,67]$. Studies have examined the effect of AEOL-10150 on tumor cells in tumor-bearing mice with RM-9 prostate cancer undergoing radiation therapy (10 Gy). The results showed that the tumor volume reduction was more pronounced in the AEOL-10150 combined radiotherapy group. The level of HIF-1 $\alpha$ in tumor cells was significantly higher than that in the control group $(P<0.05)$. However, the level of HIF- $1 \alpha$ in tumor cells in the treatment group significantly decreased, the secretion of TNF- $\alpha$ decreased, and the secretion of IL- 4 was significantly increased. These results suggest that AEOL-10150 has no protective effect on RM-9 prostate tumors but rather has radiotherapy enhancement, which may be related to its inhibition of radiotherapy-induced release of HIF- $1 \alpha$ and changes in cytokine distribution [68].

Another hypothesis is that the antitumor effect of AEOL-10150 may be related to its pro-oxidative activity. SOD-deficient aerobic $E$. coli is a simple system that demonstrates that manganese porphyrins can shift from antioxidant activity to pro-oxidative activity. In this system, AEOL-10113 can catalyze the production of hydrogen peroxide in the presence of ascorbic acid and lead to oxidative damage and inhibition of growth in wild-type and SOD-deficient E. coli. If catalase is added to the medium, the above effects can be reversed, indicating that hydrogen peroxide is an important signaling molecule that causes growth inhibition. Further experiments using oxyR- and soxRS-deficient $E$. coli revealed that oxidative stress induced by the manganese porphyrin/ascorbic acid system activates the oxyR modulator, which in turn activates the antioxidant system, such as the induction of catalases and peroxidases enzyme production. As expected, E. coli does not upregulate the antioxidant system to remove hydrogen peroxide when hydrogen peroxide is added [69]. In addition, the catalytic antioxidant itself has an oxidative effect on NF-kB, thereby inhibiting NF-kB binding to DNA, which can be reversed by the reducing agent DTT [64]. The above studies show that manganese porphyrins do have oxidative activity. Based on the characteristics of manganese porphyrins, it can be speculated that manganese porphyrin combined with ascorbic acid in vitro has anticancer activity, and when combined with chemotherapy drugs in vivo, manganese porphyrin has a therapeutic effect on 
lymphoma, which may be caused by its promotion of oxidative activity. Notably, whether manganese porphyrins play an antioxidant or oxidative effect in vivo depends on the level of intracellular free radicals and endogenous antioxidants, oxygen utilization, superoxide anion and superoxide removal system ratio, manganese porphyrins themselves and their redox capacity and their position in the cell and bioavailability.

\section{Conclusions}

Preclinical studies have shown that AEOL-10150 has a significant antitoxic effect on chemical agents such as SM and nerve agents. AEOL-10150 is also an efficacious countermeasure to radiation damage. In addition, AEOL-10150 has the potential to be developed as a new drug against tumors, hemorrhagic reperfusion injury and so on. We believe that future studies should further clarify the subcellular distribution of AEOL-10150, thus revealing the relevant mechanisms. With the development of clinical trials in phase 1 , we will know more about the metabolism of AEOL-10150 in the human body. Basic research will further reveal the subcellular distribution characteristics of AEOL-10150, revealing its active mechanism more profoundly.

\section{Abbreviations \\ 4-HNE: 4-hydroxynonenal; ALS: Amyotrophic lateral sclerosis; ARS: Acute radiation syndrome; BAL: Bronchial alveolar lavage; BARDA: Biomedical Advanced Research and Development Authority; CEES: 2-Chloroethyl ethyl sulfide; $\mathrm{Cl}_{2}$ : Chlorine; COPD: Chronic obstructive pulmonary disease; ECE- 1: Endothelin-1; ET-1: Endothelin-1; FDA: Food and Drug Administration; HSP: Heat shock protein; MCAO: Middle cerebral artery occlusion; MIP- 2: Macrophage inflammatory protein-2; MPO: Myeloperoxidase; $\mathrm{NIH}$ : National Institutes of Health; OE: Olfactory epithelium; PARP: Poly ADP-ribose polymer- ase; PBA: Phenylbutyric acid; RT: Radiotherapy; SM: Sulfur mustard; \\ SNS: Strategic National Stockpile; SOD: Superoxide dismutase}

\section{Funding}

This work was supported by the Grants from Chinese Scientific and Technological Major Special Project (2015ZX09J15104002-002, 2016ZX09J16104).

\section{Availability of data and materials}

Please contact the author for data requests.

\section{Authors' contributions}

XRZ wrote the paper and outlined this manuscript, WXZ and YXZ provided detailed guidance throughout the article. All the authors read and approved the final manuscript

\section{Ethics approval and consent to participate}

Not applicable.

\section{Consent for publication}

Not applicable.

\section{Competing interests}

All the authors declare that they have no competing interests.

Received: 22 February 2018 Accepted: 6 August 2018

Published online: 06 September 2018

\section{References}

1. Snider VG, Farquhar ER, Allen M, Abu-Spetani A, Mukherjee A. Design and reactivity of Ni-complexes using pentadentate neutral-polypyridyl ligands: possible mimics of NiSOD. J Inorg Biochem. 2017;175:110-7.
2. Batinić-Haberle I, Spasojević I, Stevens RD, Hambright P, Fridovich I. Manganese (III) meso-tetrakis (ortho-N-alkylpyridyl) porphyrins. Synthesis, characterization, and catalysis of O-2(center dot-) dismutation. J Chem Soc Dalton Trans. 2002:13:2689-96.

3. Batinić-Haberle I, Spasojević I, Hambright P, Benov L, Crumbliss AL, Fridovich I. Relationship among redox potentials, proton dissociation constants of pyrrolic nitrogens, and in vivo and in vitro superoxide dismutating activities of manganese (III) and iron (III) water-soluble porphyrins. Inorg Chem. 1999; 38(18):4011-22

4. Aeol Pharmaceuticals, California. 2017. http://www.marketwired.com/pressrelease/aeolus-announces-publication-data-demonstrating-efficacy-aeol10150-animal-model-lung-1877146.htm. Accessed 30 Dec 2017.

5. Hu P, Wu GW, Xia Q, Mao ZW. Achievement in SOD mimics with antioxidant and anti-inflammation functions. Prog Chem. 2009;5(21):873-9.

6. Liang LP, Huang J, Fulton R, Fulton R, Pearson-Smith JN, Day BJ, Patel M Pre-clinical therapeutic development of a series of metalloporphyrins for Parkinson's disease. Toxicol Appl Pharmacol. 2017:326:34-42.

7. Aeol pharmaceuticals, California. Aeolus Initiates Phase 1 Study of AEOL 10150 in Healthy Normal Volunteers: Aeolus Pharmaceuticals (AOLS). 2017. https://finance.yahoo.com/news/aeolus-announces-presentationpharmacometric-analysis-120000901.html. Accessed 30 Dec 2017.

8. John Mcmanus. Aeolus receives BARDA decision regarding additional options for lung ARS development contract; files response to assertions made by BARDA in the notification: Aeolus pharmaceuticals (AOLS). 2017. http://www.andhranews.net/Business/2017/Aeolus-Receives-BARDADecision-Regarding-Additional-5767.htm. Accessed 30 Dec 2017.

9. Milano J, Day BJ. A catalytic antioxidant metalloporphyrin blocks hydrogen peroxide-induced mitochondrial DNA damage. Nucleic Acids Res. 2000; 28(4):968-73.

10. Bloodsworth A, O'Donnell VB, Batinic-Haberle I, Chumley PH, Hurt JB, Day $B J$, et al. Manganese-porphyrin reactions with lipids and lipoproteins. Free Radic Biol Med. 2000;28(7):1017-29.

11. McElroy CS, Day BJ. Antioxidants as potential medical countermeasures for chemical warfare agents and toxic industrial chemicals. Biochem Pharmacol. 2016;100:1-11

12. O'Neill HC, White CW, Veress LA, Hendry-Hofer TB, Loader JE, Min E, et al. Treatment with the catalytic metalloporphyrin AEOL 10150 reduces inflammation and oxidative stress due to inhalation of the sulfur mustard analog 2-chloroethyl ethyl sulfide. Free Radic Biol Med. 2010;48(9):1188-96.

13. O'Neill HC, Orlicky DJ, Hendry-Hofer TB, Loader JE, Day BJ, White CW. Role of reactive oxygen and nitrogen species in olfactory epithelial injury by the sulfur mustard analogue 2-chloroethyl ethyl sulfide. Am J Respir Cell Mol Biol. 2011;45(2):323-31.

14. Tewari-Singh N, Inturi S, Jain AK, Agarwal C, Orlicky DJ, White CW, et al. Catalytic antioxidant AEOL 10150 treatment ameliorates sulfur mustard analog 2-chloroethyl ethyl sulfide-associated cutaneous toxic effects. Free Radic Biol Med. 2014;72:285-95.

15. McElroy CS, Min E, Huang J, Loader JE, Hendry-Hofer TB, Garlick RB, et al. From the cover: catalytic antioxidant rescue of inhaled sulfur mustard toxicity. Toxicol Sci. 2016;154(2):341-53.

16. Chang W, Chen J, Schlueter CF, Rando RJ, Pathak YV, Hoyle GW. Inhibition of chlorine-induced lung injury by the type 4 phosphodiesterase inhibitor rolipram. Toxicol Appl Pharmacol. 2012;263(2):251-8.

17. White CW, Martin JG. Chlorine gas inhalation: human clinical evidence of toxicity and experience in animal models. Proc Am Thorac Soc. 2010;7(4):257-63.

18. McGovern T, Day BJ, White CW, Powell WS, Martin JG. AEOL10150: a novel therapeutic for rescue treatment after toxic gas lung injury. Free Radic Biol Med. 2011;50(5):602-8.

19. Wang JY, Mu XY, Li YH, Xu FJ, Long W, Yang J, et al. Hollow PtPdRh nanocubes with enhanced catalytic activities for in vivo clearance of radiation-induced ROS via surface-mediated bond breaking. Small. 2018; 14(13):e1703736

20. Xie J, Wang N, Dong X, Wang C, Du Z, Mei L, et al. Graphdiyne nanoparticles with high free radical scavenging activity for radiation protection. ACS Appl Mater Interfaces. 2018; https://doi.org/10.1021/acsami.8b00949.

21. Martinez RM, Fattori V, Saito P, Melo CBP, Borghi SM, Pinto IC, et al. Lipoxin $\mathrm{A}_{4}$ inhibits UV radiation-induced skin inflammation and oxidative stress in mice J Dermatol Sci. 2018:1811(18):30201-9.

22. Murigi FN, Mohindra P, Hung C, Salimi S, Goetz W, Pavlovic R, et al. Dose optimization study of AEOL 10150 as a mitigator of radiation-induced lung injury in CBA/J mice. Radiat Res. 2015;184(4):422-32. 
23. Shishkina LN. Peculiarities of antioxidants as radioprotectors under radiation damage of different extent. Radiats Biol Radioecol. 2013;53(5):536-44. (Article in Russian)

24. Thomson NC. Targeting oxidant-dependent mechanisms for the treatment of respiratory diseases and their comorbidities. Curr Opin Pharmacol. 2018:40:1-8.

25. Rabbani ZN, Batinic-Haberle I, Anscher MS, Huang J, Day BJ, Alexander E, et al. Long-term administration of a small molecular weight catalytic metalloporphyrin antioxidant AEOL 10150 protects lungs from radiationinduced injury. Int J Radiat Oncol Biol Phys. 2007;67(2):573-80.

26. MacVittie TJ, Gibbs A, Farese AM, Barrow K, Bennett A, Taylor-Howell C. AEOL 10150 mitigates radiation-induced lung injury in the nonhuman primate: morbidity and mortality are administration schedule-dependent. Radiat Res. 2017;187(3):298-318.

27. Garofalo MC, Ward AA, Farese AM, Bennett A, Taylor-Howell C, Cui WC, et al. A pilot study in rhesus macaques to assess the treatment efficacy of a small molecular weight catalytic metalloporphyrin antioxidant (AEOL 10150) in mitigating radiation-induced lung damage. Health Phys. 2014;106(1):73-83.

28. Salahuddin F, Rabbani Z, Yamnolenko P, Batinic-Haberle I, Thrasher B, Gauter-Fleckenstein B, et al. High dose of low molecular weight catalytic metalloporphyrin antioxidant AEOL 10150 protects lungs from fractionated radiation. Int J Radiat Oncol Biol Phys. 2007;69(3):S484.

29. Rabbani ZN, Salahuddin FK, Yarmolenko P, Batinic-Haberle I, Thrasher BA, Gauter-Fleckenstein B, et al. Low molecular weight catalytic metalloporphyrin antioxidant AEOL 10150 protects lungs from fractionated radiation. Free Radic Res. 2007:41(11):1273-82.

30. Jackson IL, Zhang X, Hadley C, Hadley C, Rabbani ZN, Zhang Y, Marks S, et al. Temporal expression of hypoxia-regulated genes is associated with early changes in redox status in irradiated lung. Free Radic Biol Med. 2012;53(2):337-46.

31. Zhang $Y$, Zhang $X$, Rabbani ZN, Jackson IL, Vujaskovic Z. Oxidative stress mediates radiation lung injury by inducing apoptosis. Int J Radiat Oncol Biol Phys. 2012;83(2):740-8.

32. Sonis S, Patel M, Gammans R. AEOL 10150, a catalytic antioxidant, reduces the incidence and duration of radiation-induced oral mucositis in a hamster. Eur J Cancer. 2001;37(S6):S361.

33. Niemann B, Rohrbach S, Miller MR, Newby DE, Fuster V, Kovacic JC. Oxidative stress and cardiovascular risk: obesity, diabetes, smoking, and pollution: part 3 of a 3-part series. J Am Coll Cardiol. 2017;70(2):230-51.

34. Smith KR, Uyeminami DL, Kodavanti UP, Crapo JD, Chang LY, Pinkerton KE. Inhibition of tobacco smoke-induced lung inflammation by a catalytic antioxidant. Free Radic Biol Med. 2002;33(8):1106-14.

35. Pinkerton KE, Smith KR, Kodavanti U, Chang LY, Crapo JD. Attenuation of cigarette smoke-induced lung inflammation and remodeling by treatment with the metalloporphyrin (AEOL 10150). Free Radic Biol Med. 2001;31:S49.

36. Rahman I, Kilty I. Antioxidant therapeutic targets in COPD. Curr Drug Targets. 2006;7(6):707-20.

37. Rahman I, Adcock IM. Oxidative stress and redox regulation of lung inflammation in COPD. Eur Respir J. 2006;28(1):219-42.

38. Rahman I. Antioxidant therapies in COPD. Int J Chron Obstruct Pulmon Dis. 2006;1(1):15-29.

39. Zuo L, Chuang CC, Clark AD, Garrison DE, Kuhlman JL, Sypert DC. Reactive oxygen species in COPD-related vascular remodeling. Adv Exp Med Biol. 2017;967:399-411.

40. Yu W, Gao D, Jin W, Liu S, Qi S. Propofol prevents oxidative stress by decreasing the ischemic accumulation of succinate in focal cerebral ischemia-reperfusion injury. Neurochem Res. 2018;43(2):420-9.

41. Sheng H, Enghild JJ, Bowler R, Patel M, Batinić-Haberle I, Calvi CL, et al. Effects of metalloporphyrin catalytic antioxidants in experimental brain ischemia. Free Radic Biol Med. 2002;33(7):947-61.

42. Warner DS, Homi H, Crapo JD, Pearlstein RD, Sheng H. Intravenous administration of the Mn metalloporphyrin catalytic antioxidant aeol 10150 protects against ischemic brain injury in mice. Society for Neuroscience Abstract Viewer and Itinerary Planner. 2002; Abstract No. 201.18.

43. Bowler RP, Sheng H, Enghild JJ, Pearlstein RD, Warner DS, Crapo JD. A catalytic antioxidant (AEOL 10150) attenuates expression of inflammatory genes in stroke. Free Radic Biol Med. 2002;33(8):1141-52.

44. Liu XH, Harlow L, Graham ZA, Bauman WA, Cardozo C. Spinal cord injury leads to hyperoxidation and nitrosylation of skeletal muscle ryanodine receptor-1 associated with upregulation of nicotinamide adenine dinucleotide phosphate oxidase 4. J Neurotrauma. 2017;34(12):2069-74.
45. Sheng H, Spasojevic I, Warner DS, Batinić-Haberle I. Mn (iii) Meso Tetrakis (N,N'-diethylimidazolium-2-yl) porphyrin (AEOL-10150) offers protection in mouse model of spinal cord injury. Free Radic Biol Med. 2003;35:S154.

46. Sheng H, Spasojevic I, Warner DS, Batinić-Haberle I. Mouse spinal cord compression injury is ameliorated by intrathecal cationic manganese (III) porphyrin catalytic antioxidant therapy. Neurosci Lett. 2004;366(2):220-5.

47. Marrali G, Casale F, Salamone P, Fuda G, Caorsi C, Amoroso A, et al. NADPH oxidase (NOX2) activity is a modifier of survival in ALS. J Neurol. 2014; 261(11):2178-83.

48. Crow JP, Calingasan NY, Chen JY, Hill JL, Beal MF. Manganese porphyrin given at symptom onset markedly extends survival of ALS mice. Ann Neurol. 2005;58(2):258-65.

49. Petri S, Kiaei M, Kipiani K, Chen JY, Calingasan NY, Crow JP, et al. Additive neuroprotective effects of a histone deacetylase inhibitor and a catalytic antioxidant in a transgenic mouse model of amyotrophic lateral sclerosis. Neurobiol Dis. 2006;22(1):40-9.

50. Benatar M. Lost in translation: treatment trials in the SOD1 mouse and in human ALS. Neurobiol Dis. 2007;26(1):1-13.

51. Xiao F, Ma L, Zhao M, Smith RA, Huang G, Jones PM, et al. APT070 (mirococept), a membrane-localizing C3 convertase inhibitor, attenuates early human islet allograft damage in vitro and in vivo in a humanized mouse model. Br J Pharmacol. 2016;173:575-87.

52. Bottino R, Balamurugan AN, Bertera S, Pietropaolo M, Trucco M, Piganelli JD. Preservation of human islet cell functional mass by anti-oxidative action of a novel SOD mimic compound. Diabetes. 2002;51(8):2561-7.

53. Bottino R, Balamurugan AN, Tse H, Thirunavukkarasu C, Ge XH, Profozich J, et al. Response of human islets to isolation stress and the effect of antioxidant treatment. Diabetes. 2004;53(10):2559-68.

54. Pedulla M, d'Aquino R, Desiderio V, de Francesco F, Puca A, Papaccio G. MnSOD mimic compounds can counteract mechanical stress and islet beta cell apoptosis, although at appropriate concentration ranges. J Cell Physiol. 2007;212(2):432-8

55. Wei L, Zhang J, Yang ZL, You H. Extracellular superoxide dismutase increased the therapeutic potential of human mesenchymal stromal cells in radiation pulmonary fibrosis. Cytotherapy. 2017;19(5):586-602.

56. Kliment CR, Suliman HB, Tobolewski JM, Reynolds CM, Day BJ, Zhu XD, et al. Extracellular superoxide dismutase regulates cardiac function and fibrosis. J Mol Cell Cardiol. 2009:47(5):730-42.

57. Coelho SC, Berillo O, Caillon A, Ouerd S, Fraulob-Aquino JC, Barhoumi T, et al. Three-month endothelial human endothelin-1 overexpression causes blood pressure elevation and vascular and kidney injury. Hypertension. 2018;71(1):208-16.

58. Mathur S, Pollock JS, Mathur S, Harshfield GA, Pollock DM. Relation of urinary endothelin-1 to stress-induced pressure natriuresis in healthy adolescents. J Am Soc Hypertens. 2018;12(1):34-41.

59. Chen QM, Maltagliati AJ. Nrf2 at the heart of oxidative stress and cardiac protection. Physiol Genomics. 2018:50(2):77-97.

60. Niki E. Oxidant-specific biomarkers of oxidative stress. Association with atherosclerosis and implication for antioxidant effects. Free Radic Biol Med. 2018;120:425-40.

61. Ganesh D, Kumarathasan P, Thomson EM, St-Germain C, Blais E, Crapo J, et al. Impact of superoxide dismutase mimetic AEOL 10150 on the endothelin system of fischer 344 rats. PLoS One. 2016:11(3):e0151810.

62. Qu J, Li Y, Zhong W, Gao P, Hu C. Recent developments in the role of reactive oxygen species in allergic asthma. J Thorac Dis. 2017;9(1):E32-43.

63. Tse HM, Milton MJ, Piganelli JD. Mechanistic analysis of the immunomodulatory effects of a catalytic antioxidant on antigen-presenting cells: implication for their use in targeting oxidation-reduction reactions in innate immunity. Free Radic Biol Med. 2004;36(2):233-47.

64. Bowler RP, Arcaroli J, Abraham E, Patel M, Chang LY, Crapo JD. Evidence for extracellular superoxide dismutase as a mediator of hemorrhage-induced lung injury. Am J Physiol Lung Cell Mol Physiol. 2003;284(4):L680-7.

65. Batinic-Haberle I, Spasojevic I, Tse HM, Tovmasyan A, Rajic Z, St Clair DK, et al. Design of $\mathrm{Mn}$ porphyrins for treating oxidative stress injuries and their redox-based regulation of cellular transcriptional activities. Amino Acids. 2012;42(1):95-113

66. Block Kl. Antioxidants and cancer therapy: furthering the debate. Integr Cancer Ther. 2004;3(4):342-8.

67. Fuchs-Tarlovsky $\vee$. Role of antioxidants in cancer therapy. Nutrition. 2013; 29(1):15-21. 
68. Gridley DS, Makinde AY, Luo X, Rizvi A, Crapo JD, Dewhirst MW, et al. Radiation and a metalloporphyrin radioprotectant in a mouse prostate tumor model. Anticancer Res. 2007;27(5A):3101-9.

69. Batinic-Haberle I, Rajic Z, Benov L. A combination of two antioxidants (an SOD mimic and ascorbate) produces a pro-oxidative effect forcing Escherichia coli to adapt via induction of oxyR regulon. Anti Cancer Agents Med Chem. 2011;11(4):329-40.

Ready to submit your research? Choose BMC and benefit from:

- fast, convenient online submission

- thorough peer review by experienced researchers in your field

- rapid publication on acceptance

- support for research data, including large and complex data types

- gold Open Access which fosters wider collaboration and increased citations

- maximum visibility for your research: over $100 \mathrm{M}$ website views per year

At $\mathrm{BMC}$, research is always in progress.

Learn more biomedcentral.com/submissions 